\title{
Improving the Track Friendliness of a Four-Axle Railway Vehicle Using an Inertance-Integrated Lateral Primary Suspension
}

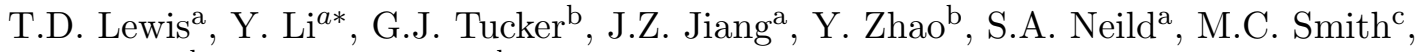 \\ R. Goodall ${ }^{\mathrm{b}}$ and N. Dinmore ${ }^{\mathrm{d}}$ \\ ${ }^{a}$ Faculty of Engineering, University of Bristol, UK; ${ }^{b}$ Institute of Railway Research, \\ University of Huddersfield, UK; ${ }^{d}$ Department of Engineering, University of Cambridge, UK; \\ ${ }^{e}$ RSSB, London, UK. WORD COUNT: $\sim 7000$ words
}

\section{ARTICLE HISTORY}

Compiled June 11, 2019

\begin{abstract}
Improving the track friendliness of a railway vehicle can make a significant contribution to improving the overall cost effectiveness of the rail industry. Rail surface damage in curves can be reduced by using vehicles with a lower Primary Yaw Stiffness (PYS); however, a lower PYS can reduce high-speed stability and have a negative impact on ride comfort. Previous studies have shown that this trade-off between track friendliness and passenger comfort can be successfully combated by using an inerter in the primary suspension; however, these previous studies used simplified vehicle models, contact models, and track inputs. Considering a realistic four-axle passenger vehicle model, this paper investigates the extent to which the vehicle's PYS can be reduced with inertance-integrated primary lateral suspensions without increasing Root Mean Square (RMS) lateral accelerations when running over a $5 \mathrm{~km}$ example track. The vehicle model, with inertance-integrated primary lateral suspensions, has been created in VAMPIRE ${ }^{\circledR}$, and the vehicle dynamics are captured over a range of vehicle velocities and wheel-rail equivalent conicities. Based on systematic optimisations using network-synthesis theory, several beneficial inertance-integrated configurations are identified. It is found that with such beneficial configurations, the PYS can be reduced by up to $47 \%$ compared to a base case vehicle, without increasing lateral RMS accelerations. This could result in a potential Network Rail Variable Usage Charge saving of $26 \%$. With the beneficial inertance-integrated suspensions, further simulations are carried out to investigate the vehicle's performance in curve transitions and when subject to one-off peak lateral track irregularities.
\end{abstract}

\section{KEYWORDS}

Inertance-Integrated Networks, Suspension, Vibration, Railway Vehicle.

\section{Introduction}

The task of concurrently optimising the straight running and curving performances of railway vehicles is highly challenging. During curving, a decreased Primary Yaw Stiffness (PYS) results in a reduction in the wheel-rail contact forces, and therefore lower rates of rail surface damage. The Network Rail Variable Usage Charge (VUC) [1], includes a calculation of the marginal cost of rail surface damage caused by rail vehicles

\footnotetext{
*Corresponding author. Email: yl14470@bristol.ac.uk
} 
based on the parameter, $\mathrm{T}_{\gamma}[2]$ (wheel-rail tangential force multiplied by wheel-rail tangential creepage, or the energy lost at the contact patch) calculated across a range of sample curves across the railway network which differ in severity. The VUC can therefore be used to quantify the benefits of a lower PYS. A decrease in PYS can cause higher carbody lateral accelerations in response to track irregularities; which can lead to instability, increasing the risk of derailment. Conventional passive railway vehicle suspensions cannot effectively combat the trade-off between trackwear and ride comfort. Active control methods have been successfully established, e.g. [3-5], addressing both straight running and curving performance. Whilst improved vibration suppression can be achieved using active rather than passive suspension components, risks such as measurement error and actuator malfunction, as well as problems associated with additional power requirements and low fault tolerances have prevented the wide-spread application of these solutions.

An inerter [6] is a two-terminal mechanical element which resists motion via a force proportional to the relative acceleration between its terminals. The proportionality constant is named inertance and measured in $\mathrm{kg}$. With the introduction of the inerter, a complete analogy between mechanical systems and electrical circuits can be obtained [6]. The range of frequency and amplitude dependent properties achievable with passive suspension systems has therefore been fundamentally enlarged. First proposed in 2002 in the form of a rack and pinion design [6], other inerter designs have been proposed such as fluid inerters [7-9], the ball-screw inerter used in Formula 1 [10], and hydraulic inerters [11]. The effective gearing mechanisms in such devices can enable the inertance to be substantially greater than the device mass, allowing a relatively lightweight device exhibiting a large inertance to be created. The performance benefits of using inerter-based suspensions have been illustrated in road vehicles [12-14], buildings [1517], aircraft landing gear [18,19] and optical tables [20].

Research into the use of inerters in railway vehicles is ongoing and significant benefits have already been demonstrated. In [21], a layout where an inerter is inserted or placed in parallel with other suspension components was shown to decrease a railway vehicle's settling time, improve its passenger comfort and increase its critical speed in response to a lateral impulse to the front wheelset. In [22], considering a 16 Degree of Freedom (DoF) two-stage suspension railway model in AutoSim ${ }^{\mathrm{TM}}$, the critical speed was shown to increase when configurations that include a parallel inerter layout are used in the secondary suspension. Using a bogied 7 DoF model, the work in [23] concluded that further ride comfort improvements can be obtained by including an inerter into both the primary and the secondary lateral suspensions, and research in [24] provides a detailed summary of the potential benefits inerters can bring to both two-axle and bogied railway vehicles in terms of stability, ride comfort and trackwear. Research into using inerters in conjunction with active mechatronic vibration suppression strategies [25] demonstrates that adding an inerter to a two-axle vehicle's vertical suspension with a skyhook damping strategy can reduce the active force requirement by $50 \%$, whilst improving the vertical ride quality by $30 \%$ over a passive system. The analysis of a two-axle railway vehicle in [26] investigating curving performance concluded that it is possible to reduce the PYS, hence lower the contact patch forces, whilst inerter-based lateral suspension configurations ensure the ride quality is as good as the default value. Inerters also provide significant benefits to the vertical and lateral ride quality when used in the vertical and lateral suspension respectively, as identified in [27]. The work of [28] demonstrates that significant concurrent improvements in both ride comfort and trackwear of a two-axle vehicle are possible when inerter-based structures are used in the lateral suspension, and the trade-off is improved further 
when an optimised trailing arm bush, including hydraulic damping in the longitudinal direction, is included. Trailing arm suspensions including longitudinal hydraulic damping already exist; e.g. the HALL-bush [29], which enables the PYS to be reduced, reducing trackwear, whilst maintaining a satisfactory level of ride comfort.

Although previous work investigating the application of inerters to rail vehicles' suspensions suggests very promising results, the models used are simple ones, consisting of relatively few DoF, simplified wheel-rail contact models, and a limited range of operating conditions. There is therefore a strong need for numerical validation of these results using more realistic models, subjected to more realistic track conditions. The research in this paper focuses on the systematic optimisation of primary lateral inertance-integrated suspensions in a realistic four-axle passenger railway vehicle model, with the aim of minimising the PYS whilst maintaining a satisfactory level of ride comfort. The vehicle dynamics are simulated in VAMPIRE ${ }^{\circledR}$, a widely-used railway vehicle modelling software with the ability to accurately model a wide variety of vehicles, including any nonlinearities, under numerous external forcings and track conditions. To simulate the inerter-based suspensions directly, the inerter modelling in VAMPIRE ${ }^{\circledR}$ has been developed in [30] and will be further improved and verified in this work. This paper details the significant improvements that optimised inerter-based suspensions in the primary suspension can bring in terms of trackwear reduction and passenger comfort improvement, at a range of wheel conicities and vehicle speeds, and lastly performs further analysis on the optimised vehicles using nonlinear wheel-rail contact data and nonlinear creep analysis, and additional vehicle dynamics assessments based on industrial standard requirements.

The structure of this paper is as follows. Section 2 introduces the vehicle model used, and the process by which the inerter device is implemented in VAMPIRE ${ }^{\circledR}$. Candidate primary lateral suspension layouts are then proposed using network-synthesis theory, i.e. the structure immittance approach. Section 3 details the optimised design of the primary suspension using both non-inertance rubber bushes and candidate inertance-integrated layouts proposed in Section 2. VAMPIRE ${ }^{\circledR}$ simulations and MATLAB ${ }^{\circledR}$ optimisation commands are used in conjunction in this process. Linear wheel-rail contact models are employed for efficiency of computation, and a range of wheel conicities and vehicle velocities are considered. Section 4 assesses the performance of the suspension designs identified with the optimisation process when the performance checks are repeated using measured wheel-rail pairs and a non-linear wheel-rail creep force calculation. Checks are carried out to see if the addition of inerters to the suspension compromises the vehicle's performance in curve transitions and when subject to one-off peak lateral track irregularities. Finally, overall conclusions are drawn in Section 5.

\section{Modelling of a Four-Axle Passenger Vehicle Including Inertance-Integrated Suspensions}

This section details the VAMPIRE ${ }^{\circledR}$ four-axle vehicle model used in this paper, including details on how the inerter is included. This vehicle is representative of a typical multiple unit passenger vehicle with a maximum operating speed of $75 \mathrm{mph}$ $\left(33.5 \mathrm{~ms}^{-1}\right)$. Candidate inertance-integrated layouts for the primary lateral suspension are proposed using the structure-immittance approach. These are then optimised for the vehicle model in Section 3. Note that the design method for inertance-integrated suspensions proposed in this paper can be applied to other railway vehicle models. 


\subsection{The Four-Axle Passenger Vehicle Model in VAMPIRE ${ }^{\circledR}$}

As introduced in Section 1, this work focuses on reducing PYS, and hence rates of rail surface damage, using inertance-integrated primary suspensions, whilst maintaining ride comfort. The analysis presented in this paper is based on the Vehicle Track Interaction Strategic Model (VTISM) [31] library vehicle: 'BogiePassenger 39t 15yaw'. It is a four-axle model which is representative of a typical multiple unit passenger vehicle that operates up to $33.5 \mathrm{~ms}^{-1}$ and weighs 39 tonnes. Figure 1 (a) shows a $3 \mathrm{D}$ view of the make up one of the vehicle's bogies, with the components of interest (the primary vertical spring and trailing arm bush) highlighted. Note that the bogie body itself has been removed to simplify viewing.

Figure 1(b) shows a horizontal plane schematic view of one bogie, detailing the make-up of the primary lateral and longitudinal suspensions. Note that the bogie frame, heavily simplified, is now depicted by the outer black box, and only the primary suspension components that act in the horizontal plane are shown. The red box marked (2) in Figure 1(b) shows the lateral contribution of the trailing arm bush, which will be subsequently referred to as the 'primary lateral suspension', and is the suspension which is optimised in this paper. Its default layout is shown in Figure 1(b). Table 1 lists the default suspension parameter values of the trailing arm bush, and the lateral and longitudinal shear components of the primary vertical spring. It can be seen from Figure 1(b) that the PYS of each wheelset is made up of the radial stiffness of the trailing arm bush $\left(k_{b x}\right)$ and the longitudinal shear stiffness of the primary vertical spring $\left(K_{s x}\right)$. Therefore, the PYS can be expressed as

$$
\mathrm{PYS}=2 a\left(k_{b x}+K_{s x}\right),
$$

where $a(=1 \mathrm{~m})$ denotes the semi-lateral spacing between the trailing arm bushes. Based on the stiffnesses defined in Table 1, the total PYS is $15 \mathrm{MNm} / \mathrm{rad}$; with $93 \%$ of this coming from $k_{b x}$. As the longitudinal shear stiffness arises from the primary vertical springs, this is considered fixed, hence in the optimisations the static longitudinal stiffness of the trailing arm bush $\left(k_{b x}\right)$ will be the cost function to be reduced (whilst ride comfort is maintained).

Table 1. The default suspension parameter values of the 39 tonne VTISM four-axle railway vehicle.

\begin{tabular}{llll}
\hline Parameter & Symbol & Unit & Value \\
\hline Trailing arm bush lateral static stiffness & $\mathrm{k}_{b y}$ & $\mathrm{MNm}^{-1}$ & 1.75 \\
Trailing arm bush lateral damping & $\mathrm{c}_{b y}$ & $\mathrm{kNsm}^{-1}$ & 1.75 \\
Trailing arm bush lateral damping end stiffness & $\mathrm{k}_{c y}$ & $\mathrm{kNsm}^{-1}$ & 3.75 \\
Primary spring lateral shear stiffness & $\mathrm{K}_{s y}$ & $\mathrm{MNm}^{-1}$ & 0.50 \\
Trailing arm bush longitudinal static stiffness & $\mathrm{k}_{b x}$ & $\mathrm{MNm}^{-1}$ & 7.00 \\
Trailing arm bush longitudinal damping & $\mathrm{c}_{b x}$ & $\mathrm{kNsm}^{-1}$ & 7.00 \\
Trailing arm bush longitudinal damping end stiffness & $\mathrm{k}_{c x}$ & $\mathrm{MNm}^{-1}$ & 14.0 \\
Primary spring longitudinal shear stiffness & $\mathrm{K}_{s x}$ & $\mathrm{MNm}^{-1}$ & 0.50 \\
\hline
\end{tabular}




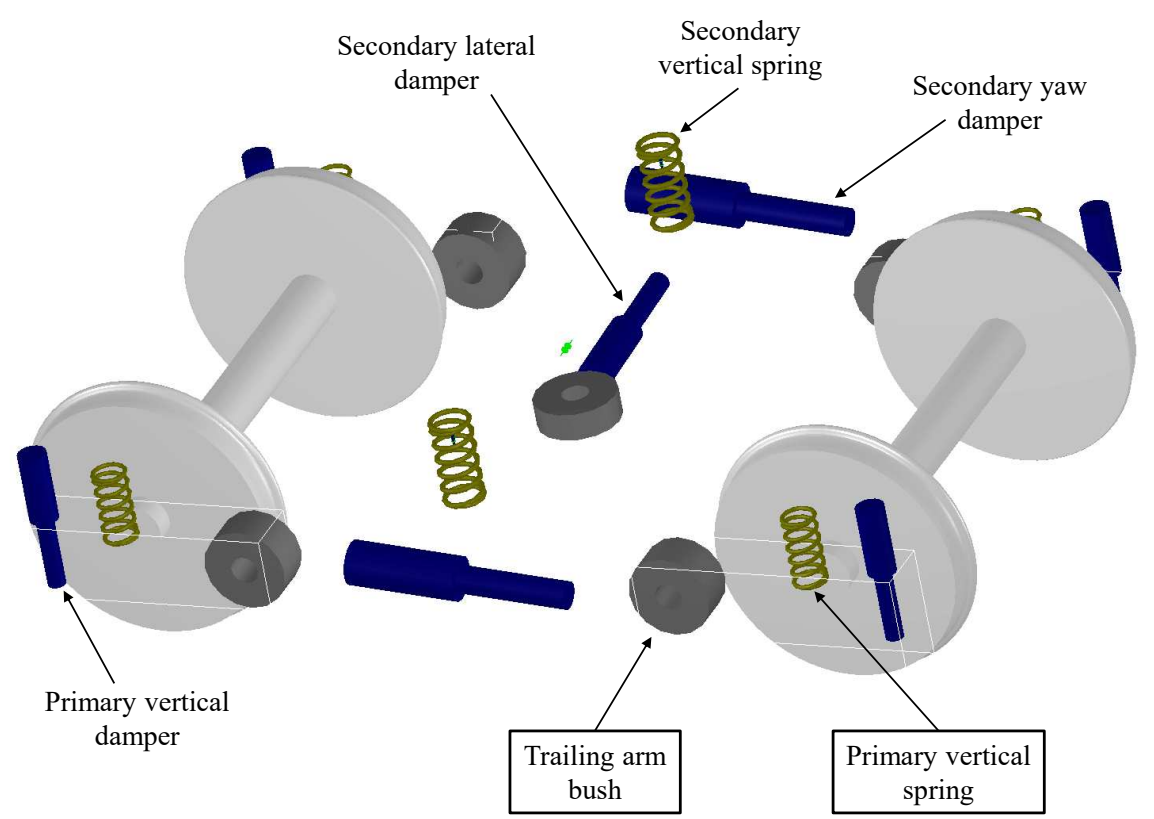

(a)

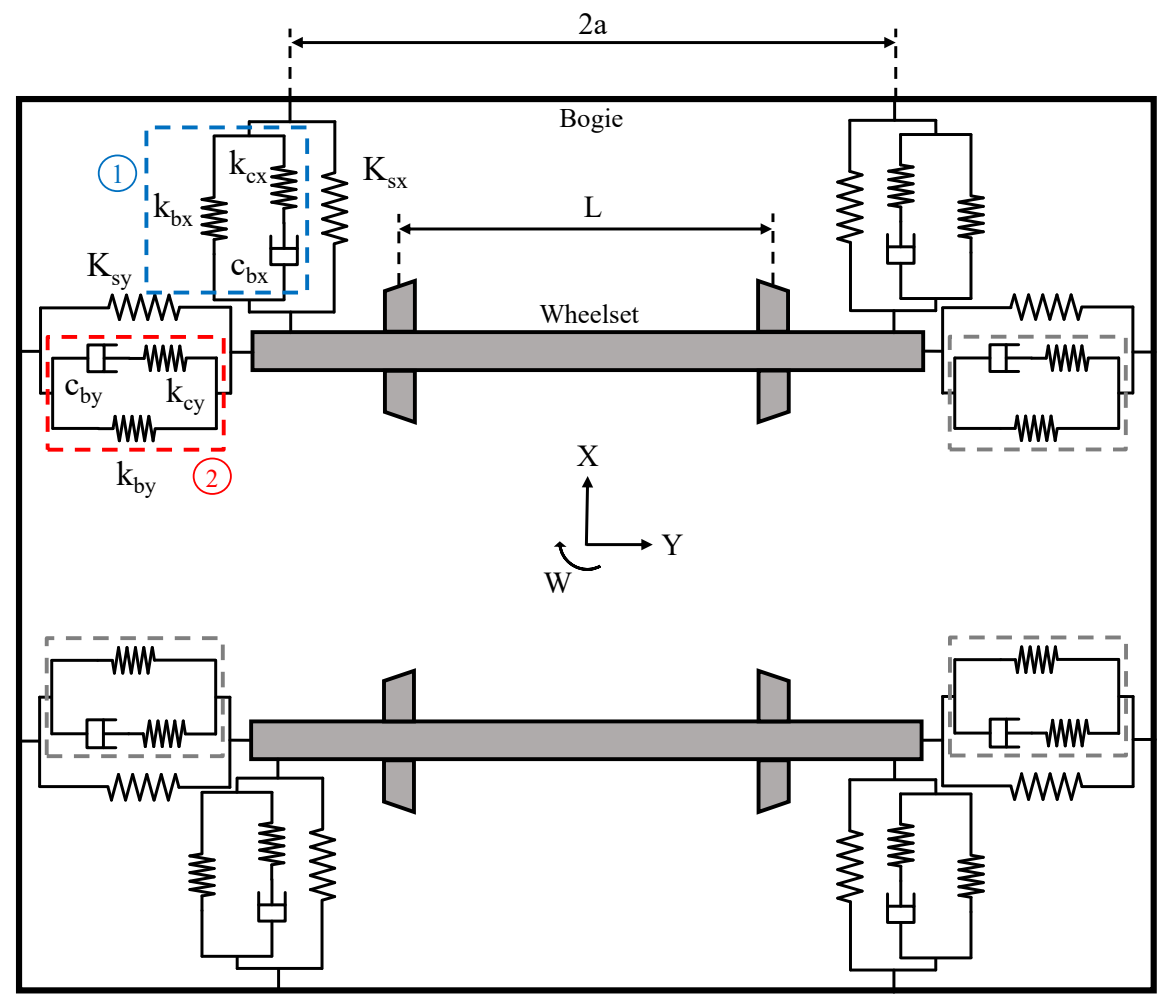

(b)

Figure 1. (a) A $3 \mathrm{D}$ view of the 'BogiePassenger 39t 15yaw' vehicle bogie, with various suspension components labelled. The boxes indicate the components that are of particular interest in this paper, and the bogie frame and corresponding connections have been removed to simplify viewing, (b) a schematic of one of the bogies in the VTISM four-axle vehicle model. Subscript 's' denotes the shear component of the primary vertical springs. Symbols (1) and (2) detail respectively the default longitudinal and lateral stiffness and damping components of the trailing arm bush. X denotes the longitudinal direction (direction of travel), Y the lateral direction, and $\mathrm{W}$ the yaw rotation. 


\subsection{Conicity and Wheel Rail Contact Modelling}

The concept of wheel-rail equivalent conicity and the methods by which contact patch creep forces are simulated are important when assessing the vehicle's dynamic behaviour. Conicity is a measure of the effective cone angle of the wheel profile with respect to the rail. This conicity, along with the wheel flange, allows the vehicle to steer around curves and resist derailment, and plays a key role when determining the vehicle's kinematic, or hunting, oscillation. The wavelength of this oscillation, the Klingel wavelength [32], is calculated from,

$$
\Lambda=2 \pi \sqrt{\frac{r_{0} L}{\lambda}}
$$

where $r_{0}$ is the nominal wheel radius, $L$ is the lateral distance between the contact points (see Figure 1(b)), and $\lambda$ is the wheel conicity. The rolling-radius-difference (between the left and the right wheel) caused by the presence of wheel conicity causes this simple harmonic oscillation, which induces the motion of numerous vehicle modes. A high conicity generally produces a short Klingel wavelength, higher carbody accelerations, and thus poorer ride comfort. The shorter Klingel wavelength arising from a lower conicity, resulting in generally lower carbody accelerations, also means that flange contact is more likely. In reality, however, the wheel profile is curved, rather than perfectly conical, and the term equivalent conicity is used [33]. Equivalent conicity of a wheelset is defined as the conicity of a perfectly conical wheelset which has the same Klingel wavelength as the wheelset in question.

To improve the computational efficiency of the optimisation in this work, linear, or constant, conicity is used in Section 3 to identify beneficial configurations, along with a linear creep law with the half creep friction saturation simplification. In Section 4 however, measured nonlinear wheel-rail contact data is used along with fully nonlinear friction saturation with a coefficient of friction value of 0.32 . It should be noted that the equivalent conicity of the measured wheel-rail contact data has been measured (or inferred from the rolling-radius-difference) at a $3 \mathrm{~mm}$ lateral offset, i.e. when the wheelset has moved $3 \mathrm{~mm}$ laterally from the centreline. In practice it is impossible to give a single value of equivalent conicity for a given wheel-rail pair, as equivalent conicity will vary with lateral offset. In the UK it is standard practice to give the equivalent conicity for a wheel-rail pair based on a lateral offset of $3 \mathrm{~mm}$.

\subsection{Inerter Modelling in VAMPIRE ${ }^{\circledR}$}

The implementation of the inerter in VAMPIRE ${ }^{\circledR}$ has been introduced in [30]. This makes use of a rack and pinion design to realise the inerter concept (see Figure 2(a)). Figure 2(b) shows the equivalent schematic flywheel type inerter connection when modelled in VAMPIRE ${ }^{\circledR}$, where the central mass is created with a pitch inertia value equal to the inertance required, and is grounded in all DoFs apart from that of pitch so it will act as a free flywheel. As the standard inerter equation cannot be inserted directly into VAMPIRE ${ }^{\circledR}$, a stiffness link equation (equivalent to $\mathrm{k}_{e}$ in Figure $2(\mathrm{~b})$ ) is used to form the inerter connection. The results of a computational study on implementing the inerter into a simple two-mass system in VAMPIRE ${ }^{\circledR}$ and in MATLAB ${ }^{\circledR}$ show that when an inerter, implemented as above, is in parallel with a static stiffness in the suspension, the main mass will experience high-frequency oscil- 
lations. This is due to the use of the stiffness link equation erroneously introducing a high-frequency mode due to an end-stiffness. This effect will not exist for an ideal inerter. To reduce such high-frequency oscillations in simulations, a damper (equivalent to $c_{e}$ in Figure 2(b)) is introduced to the link equation. In this way, the end-stiffness effects become insignificant, and a good match between the responses obtained with VAMPIRE ${ }^{\circledR}$ and MATLAB ${ }^{\circledR}$ can be obtained.

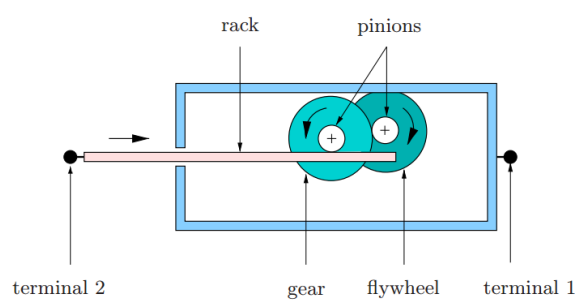

(a) Rack and pinion inerter [10].

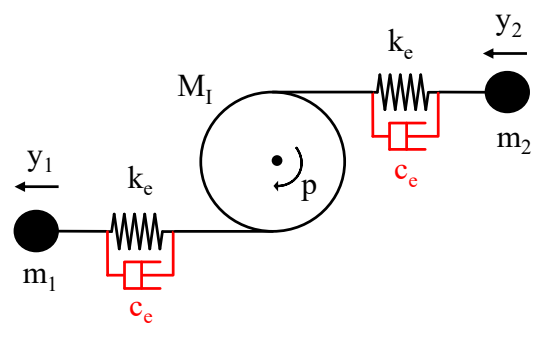

(b) VAMPIRE ${ }^{\circledR}$ schematic.

Figure 2. (a) A rack and pinion inerter device, reproduced from [10], along with (b) the equivalent schematic in VAMPIRE ${ }^{\mathbb{R}}$ which uses the stiffness link equation.

Therefore, to simulate the behaviour of an ideal inerter in VAMPIRE ${ }^{\circledR}$, both damping and stiffness link equations are needed. Note that for this complicated four-axle railway vehicle model, the high-frequency oscillations caused by an end stiffness have been mitigated due to the presence of many other dampers in the system. The damping link equation is therefore not needed here, but it is mentioned to highlight that this effect should be, and has been, considered.

\subsection{Candidate Inertance-Integrated Layouts Using the Structure Immittance Approach}

In this work, the conventional (default) layout as seen in Figure 3(a) is labelled S1 and will be optimised first. Candidate inertance-integrated layouts for the primary lateral suspensions (2) in Figure 1(b)) will be proposed using the structureimmittance approach [34]. This approach allows generic suspension structures, which can cover all potential networks with a pre-determined complexity, to be established in VAMPIRE ${ }^{\circledR}$ and explored in a systematic manner during the optimisations. The constraints on element values can also be easily applied in the optimal design process.

For simplicity of design, layouts consisting of one spring, one damper, and one inerter $\left(1_{k} 1_{c} 1_{b}\right)$ will be considered here. Following the formulation procedure detailed in [34], two generic layouts which cover all eight $\left(1_{k} 1_{c} 1_{b}\right)$ layouts are shown in Figures $3(\mathrm{~b})$ and (c). These two generic layouts are implemented in VAMPIRE ${ }^{\circledR}$ (with inerters being introduced in accordance with Section 2.3) in parallel with a fixed lateral static stiffness $\left(\mathrm{k}_{b y}\right)$ replacing the conventional primary lateral suspension. When optimising each of the generic layouts, the parameter values of the inerters, dampers and springs are varied with the condition that only one spring is present in the optimised layout and the others must take a value of zero or infinity depending on their position. Note that, if manufacturing constraints allow it, layouts with an increased complexity can also be established and investigated following the procedure developed in [34]. 


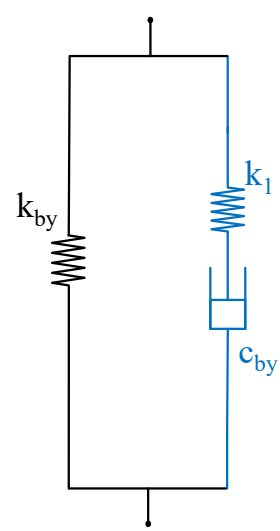

(a) $\mathrm{S} 1$

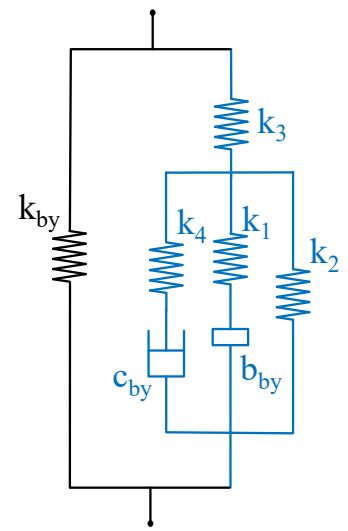

(b) Generic network 1 .

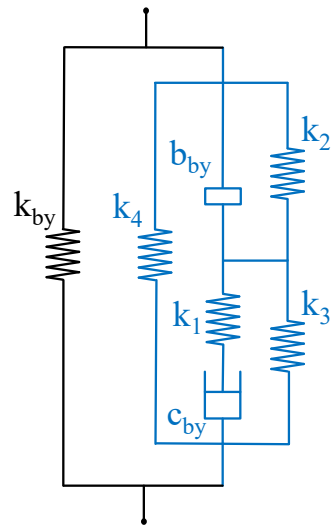

(c) Generic network 2 .

Figure 3. The default S1 Network, and the two generic networks which can be used to make up the eight layouts consisting of one inerter, one damper, and one spring.

\section{Identification of Beneficial Primary Suspension Configurations for Primary Yaw Stiffness Reduction}

This section introduces an optimisation procedure using VAMPIRE ${ }^{\circledR}$ simulations and MATLAB ${ }^{\circledR}$ optimisation commands with the aim of reducing the vehicle's PYS by optimising the primary lateral suspension without worsening ride comfort. Firstly, the default rubber bush will be optimised, then an inertance-integrated device. Three beneficial inertance-integrated layouts are identified and the corresponding performance benefits are demonstrated.

\subsection{Optimisation Cost Function, Constraints, and Procedure}

To maintain a satisfactory level of passenger comfort when reducing the vehicle's PYS, performance constraints on the comfort are considered in the optimisation. For this study, the ride comfort is quantified as the average value of the carbody's Root Mean Squared (RMS) acceleration, as measured at floor level above the centre of each bogie. Three values of linear wheel conicity $(0.1,0.3$ and 0.5$)$ and three forward vehicle speed $\left(11.2 \mathrm{~ms}^{-1}, 22.4 \mathrm{~ms}^{-1}\right.$ and $33.5 \mathrm{~ms}^{-1}$ ) cases, forming a total of nine conicity and speed combinations, are investigated to ensure a thorough analysis of the vehicle's performance. The vehicle used in this study has a rated velocity of $33.5 \mathrm{~ms}^{-1}$, and its dynamics are assessed using the VAMPIRE ${ }^{\circledR}$ library track file 'track160'. This is a $5 \mathrm{~km}$ track that is representative of a standard, straight, GB track with a line speed of $160 \mathrm{kph}$. The geometry contains irregularities in curvature, cant, lateral and vertical alignment, and gauge variations. At the two highest velocity and conicity combinations (conicity 0.3 and 0.5 at $33.5 \mathrm{~ms}^{-1}$ ) the maximum permitted RMS acceleration is constrained to $100 \%$ of the default values. However, a relaxed constraint of $110 \%$ of the default RMS values is used for the seven other cases, as these are assumed to be less critical in the control of instabilities.

The parameters of the primary lateral suspension elements are allowed to be optimised but will be constrained within certain ranges. The conventional primary lateral suspension comprises a rubber bush [31] (see Figure 3(a)), which has a limited range of achievable stiffness and damping values. This will be optimised first to demonstrate 


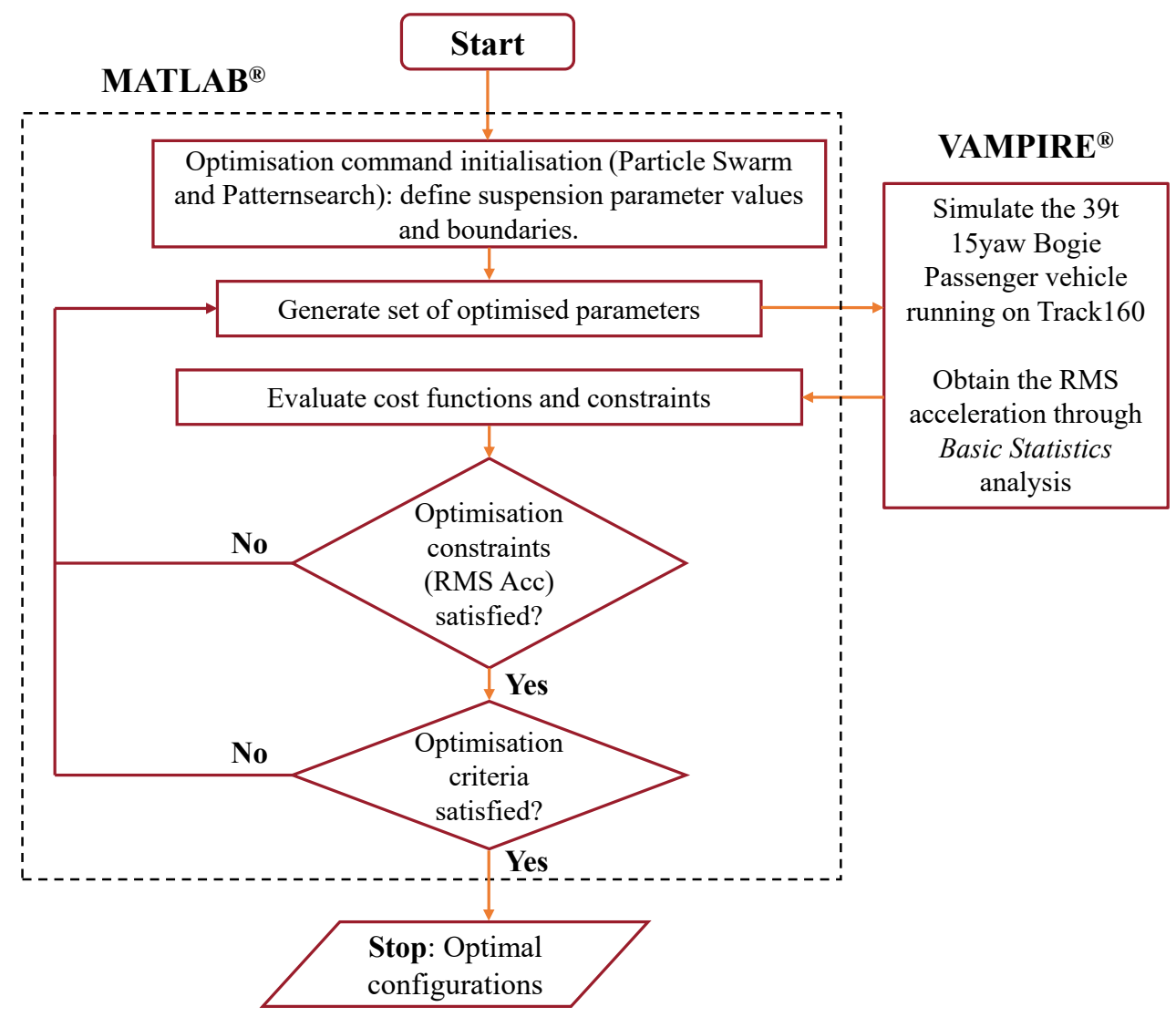

Figure 4. A flow-chart showing how MATLAB ${ }^{\circledR}$ and VAMPIRE ${ }^{\circledR}$ interact within the optimisation process.

the maximum benefits that a rubber bush can acheive. Inertance-integrated layouts introduced in Section 2.4 will then be optimised. A wider parameter space for these layouts will be assumed considering various realisation possibilities (e.g. hydraulic bushing devices with oriface induced damping, devices using ball-screw and lever arm based inertance). For example, if considering a helical-tube fluid inerter device [35,36], the inertance is given by

$$
b=m\left(\frac{A_{1}}{A_{2}}\right)^{2}=m\left(\frac{r_{1}}{r_{2}}\right)^{4}
$$

where $b$ denotes inertance, $m$ is the mass of the fluid in the tube, and respectively $A_{1}$ and $r_{1}$ the area and radius of the piston, and $A_{2}$ and $r_{2}$ the area and radius of the helical tubing. It can be calculated that a $r_{1}$ to $r_{2}$ ratio of 10 can achieve $7000 \mathrm{~kg}$ of inertance with $0.7 \mathrm{~kg}$ of fluid in the tube. Therefore, in the optimisations, for the rubber bush, the series stiffness and damping values can vary betweeen $1-5 \mathrm{MNm}^{-1}$ and $1-5 \mathrm{kNsm}^{-1}$ respectively, and for the inertance-integrated devices the ranges are $1-10 \mathrm{MNm}^{-1}$ and $1-50 \mathrm{kNsm}^{-1}$. The inertance can be allowed to take values up to $7000 \mathrm{~kg}$. Note that to form a fair comparison and maintain the vehicle's static lateral behaviour, the static stiffness, $k_{b y}$, remains fixed at a value of $1.75 \mathrm{MNm}^{-1}$ throughout the optimisation process. 
Figure 4 displays a flow-chart detailing the interaction between MATLAB ${ }^{\circledR}$ and VAMPIRE ${ }^{\circledR}$ within the optimisation procedure. MATLAB ${ }^{\circledR}$ is used to perform the optimisations (using Genetic Algorithms such as Patternsearch and Particle Swarm Optimisation (PSO) ) and calls VAMPIRE ${ }^{\circledR}$ to perform a defined simulation for each iteration. For each iteration, the cost function, $K_{b x}$, and the parameter values of the primary suspension in question are allowed to change as the optimisation inputs change. Each VAMPIRE ${ }^{\circledR}$ run consists of the vehicle being subject to track160, using a simulation time-step of $0.0001 \mathrm{~s}$.

\subsection{Optimisation Results Detailing Beneficial Suspension Configurations}

The optimisation results have been summarised in Table 2, where the variation and reduction of the total PYS is based on the optimised $k_{b x}$. The first two lines of Table 2 (default and $\mathrm{S}_{a}$ ) show that the PYS can only be reduced by $2 \%$ with an optimum rubber bush $\mathrm{S} 1_{a}$, using the parameters space detailed in Section 3.1, and the values of RMS acceleration for the default $\mathrm{S} 1$ and optimised rubber bush $\mathrm{S} 1_{a}$ are almost identical. This suggests that the default values for the primary lateral suspension used in the 'BogiePassenger 39t 15yaw' model are very similar to the optimal ones when considering only rubber bushes. To form a fair comparison, the next set of optimisation results show that when the default S1 layout is optimised with the widened parameter space (detailed in Section 3.1), the PYS is allowed to be reduced by $21 \%$ (See $\mathrm{S}_{b}$ in Table 2), as the series stiffness and damping components increase in value.

Table 2. Showing optimised parameter values when using inertance-integrated layouts, as well as the default and optimised S1 rubber bush.

\begin{tabular}{lllllll}
\hline Layout & $\begin{array}{l}\mathrm{k}_{1 y} \\
\left(\mathrm{MNm}^{-1}\right)\end{array}$ & $\begin{array}{l}\mathrm{k}_{2 y} \\
\left(\mathrm{MNm}^{-1}\right)\end{array}$ & $\begin{array}{l}\mathrm{c}_{b y} \\
\left(\mathrm{kNsm}^{-1}\right)\end{array}$ & $\begin{array}{l}\mathrm{b}_{b y} \\
(\mathrm{~kg})\end{array}$ & $\begin{array}{l}\text { PYS (abs) } \\
\text { MNmrad }^{-1}\end{array}$ & $\begin{array}{l}\text { PYS (\%) } \\
\text { of default }\end{array}$ \\
\hline Default & 3.50 & - & 1.75 & - & 15.00 & 100 \\
$\mathrm{~S}_{a}$ & 3.38 & - & 1.93 & - & 14.72 & 98 \\
$\mathrm{~S}_{b}$ & 10.00 & - & 50.00 & - & 11.92 & 79 \\
$\mathrm{~S} 2$ & 4.17 & - & 38.45 & 3905.63 & 7.99 & 53 \\
$\mathrm{~S} 3$ & 9.09 & - & 50.00 & 6829.94 & 8.83 & 59 \\
$\mathrm{~S} 4$ & 9.24 & 10.00 & 50.00 & 2550.00 & 7.99 & 53 \\
\hline
\end{tabular}

Using the candidate layouts proposed by the structure-immittance approach (see Section 2.4), several inertance-integrated configurations have been identified, as shown in Figure 5: S2-S4. Optimisation results shown in Table 2 yield PYS reductions of 47\%, $41 \%$ and $47 \%$ respectively for layouts S2, S3 and S4. Note that for S4, a damping compliance $\mathrm{k}_{2 y}$ has been included to make the modelling more realistic, as in reality all dampers have a certain amount of end stiffness.

Figure 6 details the RMS carbody acceleration values with the five optimised solutions for different conicities and velocities set out in Table 2. The horizontal dashed lines represent the default RMS acceleration value for each velocity and conicity combination, whilst the dotted lines show the relaxed $110 \%$ constraint defined in Section 3.1. Firstly, it can be seen that at conicity 0.5 and $33.5 \mathrm{~ms}^{-1}$, configurations S2, S3 and $\mathrm{S} 4$ provide significant reductions in carbody RMS acceleration (of respectively $18.5 \%$, $5.2 \%$, and $13.8 \%$ ) whilst permitting the PYS to be decreased. Note that these results are based on simulations carried out using simplified, linear contact models. At lower speeds, however, S3 and S4 perform nominally better than S2, and at conicity 0.1, all configurations are far less susceptible to changes in vehicle speed, in terms of deviating from their relative RMS acceleration performance. 

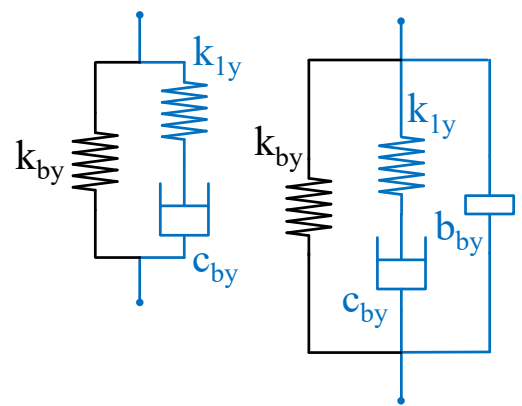

S1

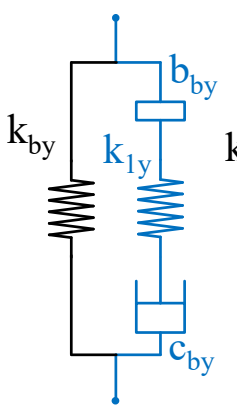

S3

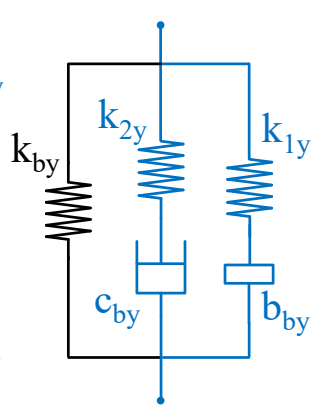

S4

Figure 5. The default bushing layout along with the three identified beneficial inertance-integrated networks.

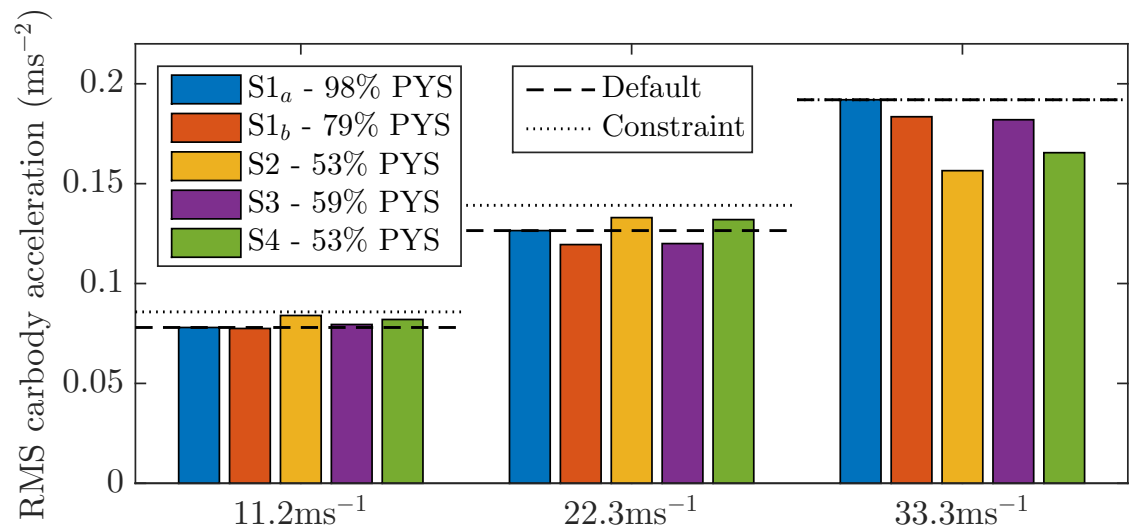

(a) Conicity 0.5 .

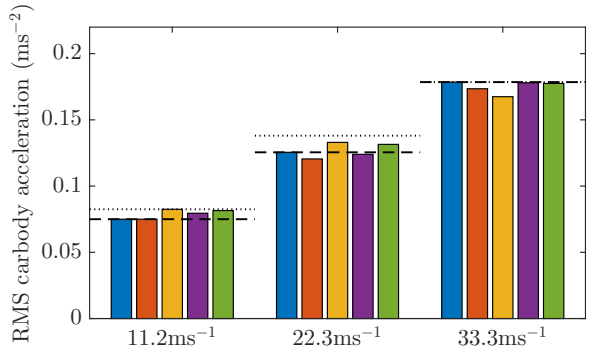

(b) Conicity 0.3

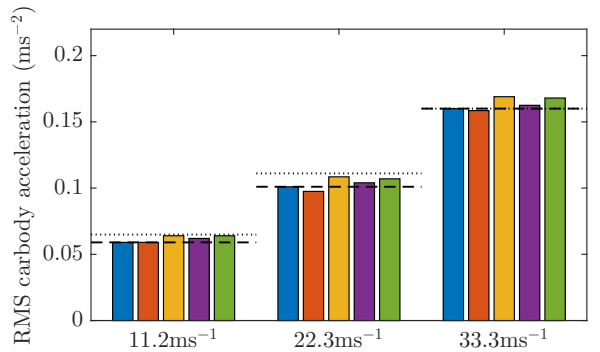

(c) Conicity 0.1 .

Figure 6. Showing how RMS carbody acceleration values vary with vehicle velocity and linear conicity, for configurations defined in Table 2 and Figure 5. The improvements in the RMS values for $\mathrm{S} 1_{b}, \mathrm{~S} 2, \mathrm{~S} 3$ and $\mathrm{S} 4$, and $\mathrm{S} 1_{a}$ (acting as the default) at conicity 0.5 and $33.5 \mathrm{~ms}^{-1}$ are respectively $4.43 \%, 18.49 \%, 5.21 \%$, and $13.8 \%$.

To understand the effect of a reduced PYS on the system without an inerter, Figure 7 shows the $\mathrm{S}_{1 b}$ layout with $53 \%$ PYS (i.e. the same PYS value that is used with the $\mathrm{S} 2$ layout). It can be seen that for the two cases with conicity 0.3 and 0.5 (at $33.5 \mathrm{~ms}^{-1}$ ) the inertance-integrated configuration S2 is far superior compared with the lower speed and conicity cases. This suggests that the inclusion of an inerter in the suspension allows the PYS to be reduced whilst improving or maintaining the ride comfort. 


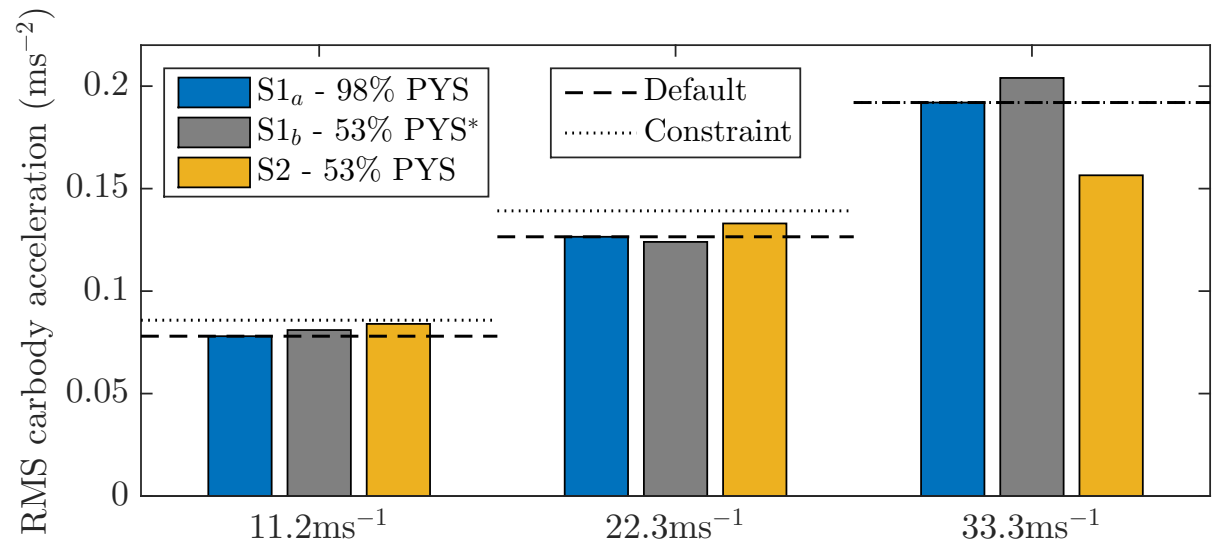

(a) Conicity 0.5 .

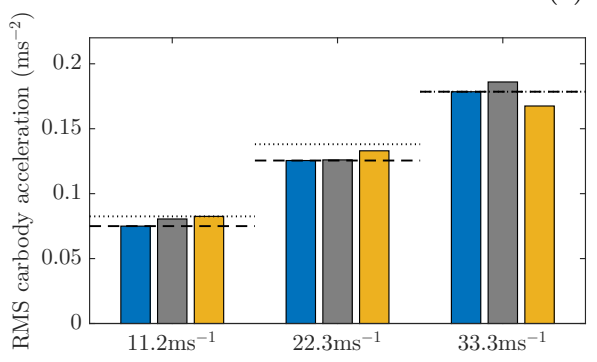

(b) Conicity 0.3 .

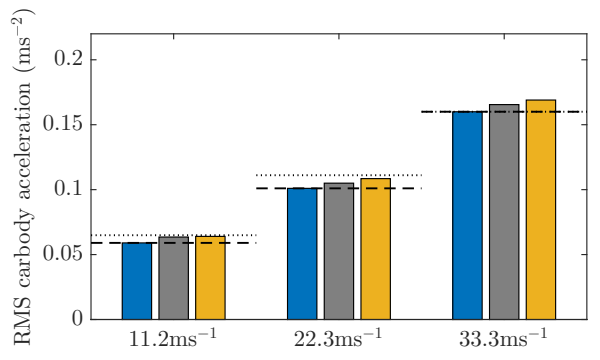

(c) Conicity 0.1 .

Figure 7. Showing configuration $\mathrm{S} 1_{b}$ with a PYS of $53 \%$ rather than $79 \%$ to demonstrate the effect of the reduced PYS on a layout without an inerter. For reference, $\mathrm{S} 1_{a}$ and the inerter-based $\mathrm{S} 2$ data are reproduced from Figure 6.

\section{Assessment of Beneficial Configurations}

The optimisation detailed in Section 3 uses simplified, linear conicity contact models and track 160 for the sake of computational efficiency. The performance of the linearly optimised devices is now considered using more realistic wheel-rail contact models. Here a nonlinear contact model based on measured wheel-rail pairs with equivalent conicities of $0.1,0.3$, and 0.5 (see Section 2.2 for details on equivalent conicity), and nonlinear creep vs creep force friction saturation is included in the model. Benefits in VUC that a reduced PYS brings are calculated, and the effects of the modified suspension design on vehicle behaviour in curve transitions and in response to one-off peak lateral irregularities are investigated. Note that no further optimisation takes place in this section.

\subsection{Carbody Acceleration Analysis Using Nonlinear Wheel-Rail Contact Data}

In this section, measured worn wheels from a previous research project [37] are used in the VAMPIRE ${ }^{\circledR}$ simulations to assess the performance advantages obtained by the use of inertance-integrated structures. The equivalent conicity of these wheel-rail pairs is calculated based on a $3 \mathrm{~mm}$ lateral offset.

Figure 8 shows the RMS accelerations with all the beneficial solutions shown in Table 2 when the nonlinear contact model is used. The horizontal dashed lines represent 
the RMS values obtained with the $\mathrm{S} 1_{a}$ configurations for each velocity and equivalent conicity case. The percentage improvements in RMS acceleration when compared with $\mathrm{S}_{a}$, for conicity 0.5 and $33.5 \mathrm{~ms}^{-1}$, are respectively $5.14 \%, 11.78 \%, 6.04 \%$, and $7.55 \%$. Comparing with the linear contact modelling case in Section 3.2 it can be observed that at $33.5 \mathrm{~ms}^{-1}$ and the highest equivalent conicity (0.5) cases, the RMS accelerations are still reduced significantly for the nonlinear case, but the reductions in percentage terms are smaller than in the corresponding linear cases. This is because the optimisation did not include nonlinear contact modelling. In addition, it is positive to observe that for lower conicity and velocity cases there are no large increases in RMS acceleration (of over 10\%).

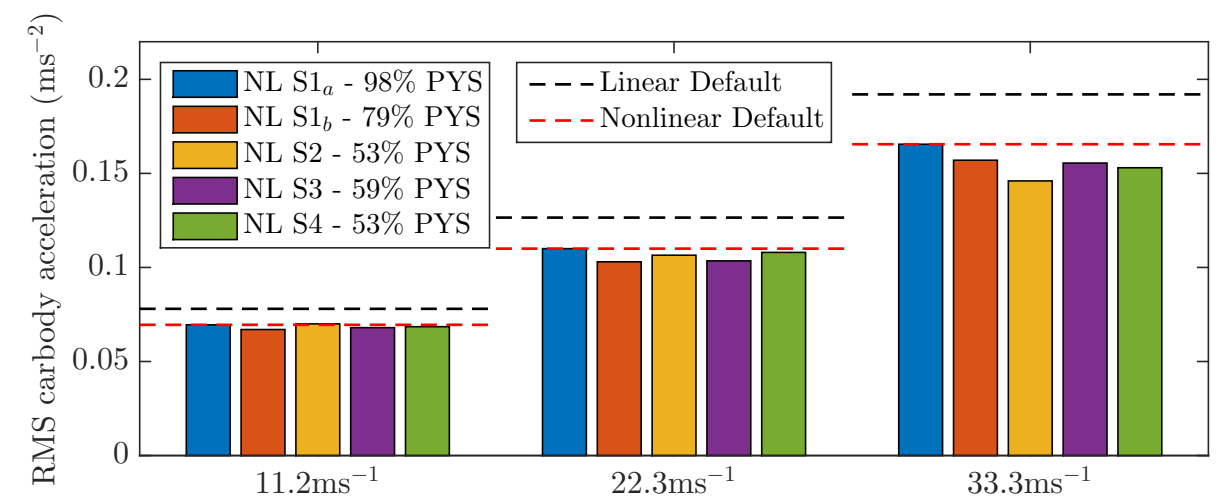

(a) Equivalent Conicity 0.5.

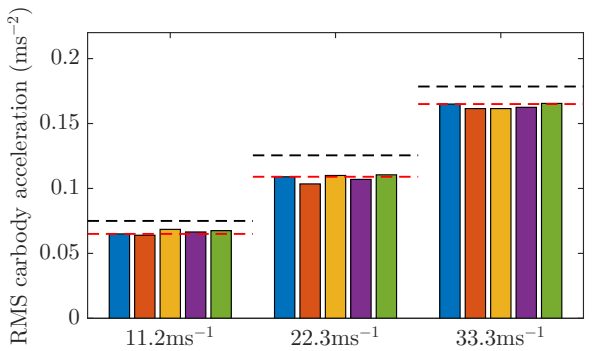

(b) Equivalent Conicity 0.3 .

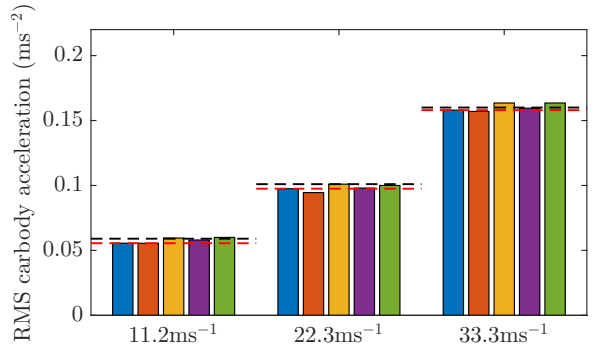

(c) Equivalent Conicity 0.1.

Figure 8. Showing the RMS vs Velocity variation for vehicle's simulated with optimal primary suspensions, now using measured wheel-rail contact data rather than linear conicity.

When comparing the nonlinear contact model simulations with the linear ones, it is observed that, for every case (conicity, velocity and configuration type), the linear contact model over-predicts RMS carbody acceleration. Furthermore, this overprediction in general is exacerbated as the conicity (or equivalent conicity) increases. This phenomenon occurs due to the fact that the equivalent conicity of the measured wheel-pairs, is measured at a lateral offset of $3 \mathrm{~mm}$, and between 0 - 3mm lateral offset, the gradient of the rolling radius difference graph will most likely be flatter.

Figure 9 shows how RMS and peak accelerations of both the carbody and the front bogie vary with equivalent conicity and a wider continuous vehicle velocity range ( 5 - $44 \mathrm{~ms}^{-1}$ ), for all the beneficial inertance-integrated layouts, plus the default. The default S1 configuration with 53\% PYS is also shown to enable a direct comparison between a vehicle with solely a significantly reduced PYS, and a vehicle with the same reduced PYS but also optimised inertance-integrated suspensions. 


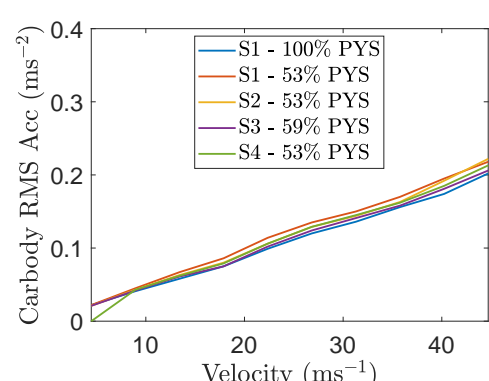

(a) Conicity 0.1.

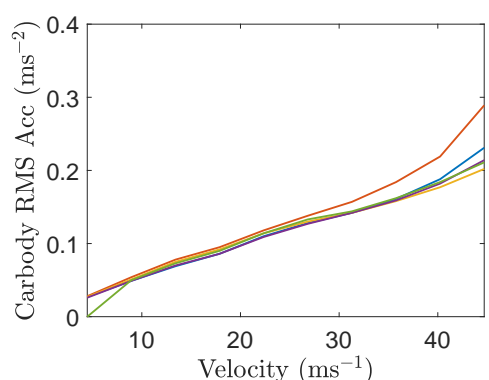

(e) Conicity 0.3.

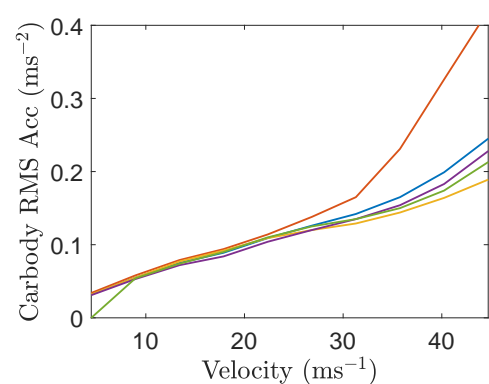

(i) Conicity 0.5

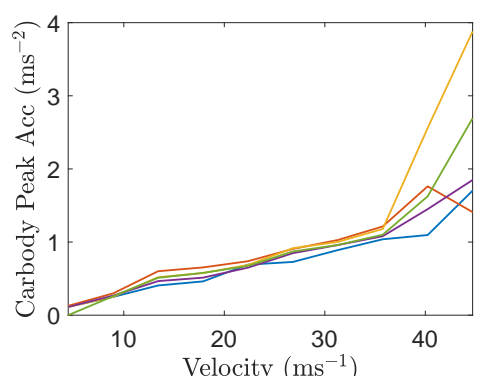

(b) Conicity 0.1.

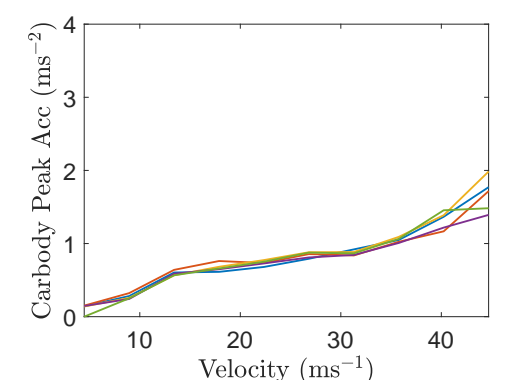

(f) Conicity 0.3.

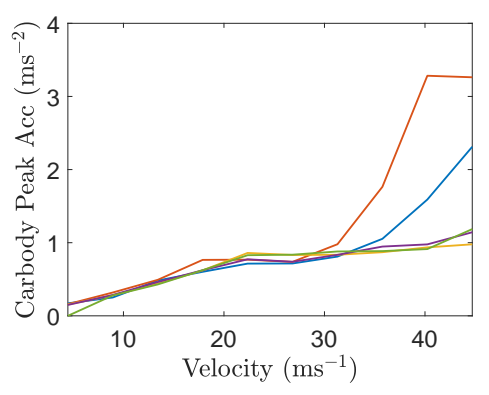

(j) Conicity 0.5.

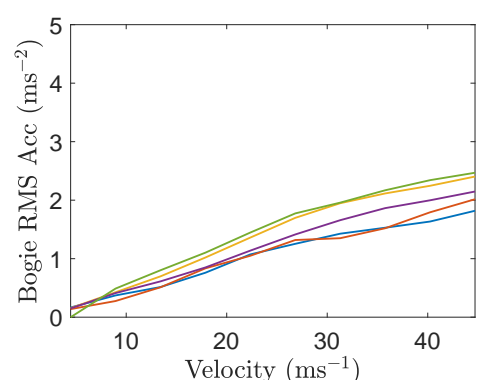

(c) Conicity 0.1.

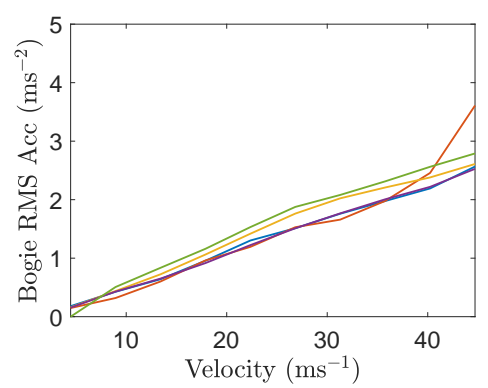

(g) Conicity 0.3.

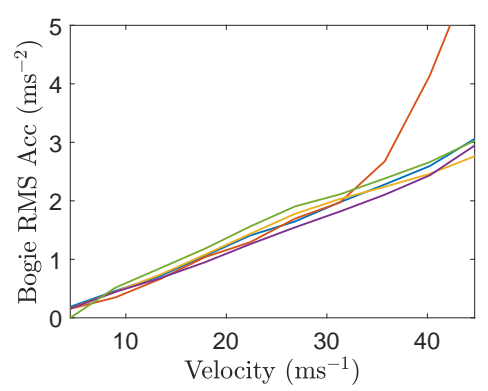

(k) Conicity 0.5 .

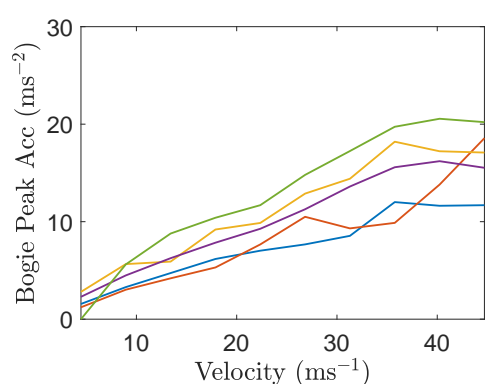

(d) Conicity 0.1 .

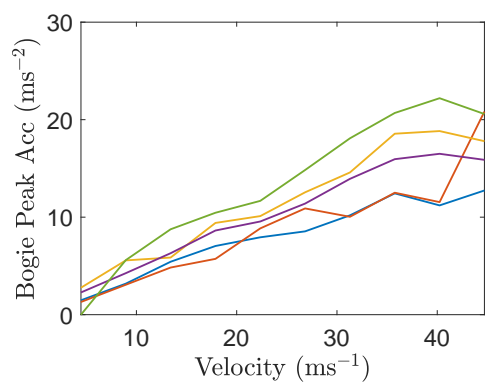

(h) Conicity 0.3

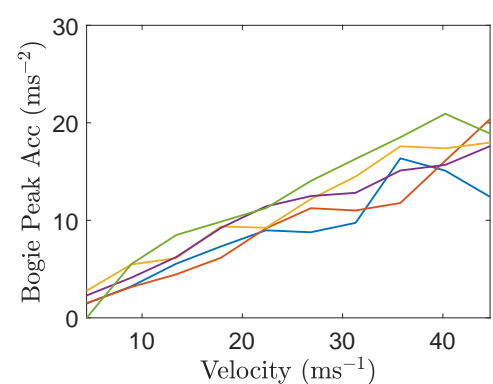

(1) Conicity 0.5

Figure 9. How different types of acceleration (Carbody RMS ((a), (e), (i)), Carbody Peak ((b), (f), (j)), Front Bogie RMS ((c), (g), (k)), Front Bogie Peak ((d), (h), (j))) vary with vehicle velocity for vehicles with the default suspension, the default suspension with $53 \%$ PYS, and the three optimal inertance-integrated suspension configurations $(\mathrm{S} 2-\mathrm{S} 4)$. 
It can be seen that in contrast to the low equivalent conicity case (0.1), the RMS carbody accelerations at the high equivalent conicity cases $(0.3$ and 0.5$)$ obtained with the beneficial inertance-integrated configurations can be reduced further at higher vehicle speeds, comparing with the default suspension. These observations are consistent with the optimisation targets introduced in Section 3 and Figure 8. From Figure 9, it can be seen that when using nonlinear wheel-rail contact data, bogie hunting behaviour begins at around $100 \mathrm{mph}\left(44.7 \mathrm{~ms}^{-1}\right)$, and that the inertance-integrated suspensions S2 and S4 can induce higher peak and high frequency accelerations on the bogie and carbody; however, when an inerter is placed in series with a damper (S3), these effects are minimised (see Figure 9(b)). In general, the default suspension (S1) with a PYS of $53 \%$ exhibits higher accelerations than the other configurations at higher velocities. Accelerations reduce with the introduction of the optimised inertance-integrated networks, most notably in the case of RMS acceleration, but also to an extent for peak accelerations.

A Power Spectral Density (PSD) analysis of the carbody's lateral motion above the front bogie at equivalent conicity 0.5 and $0.3\left(\right.$ at $\left.33.5 \mathrm{~ms}^{-1}\right)$ for all six configurations considered in Table 2 can be seen in Figure 10. Note that $\mathrm{S} 1$ and $\mathrm{S} 1_{a}$ lines are similar throughout. The benefits of the inertance-integrated structures to ride comfort are most prominent above $4 \mathrm{~Hz}$; and very slightly worse behaviour can be seen within the lower rigid body frequency range.

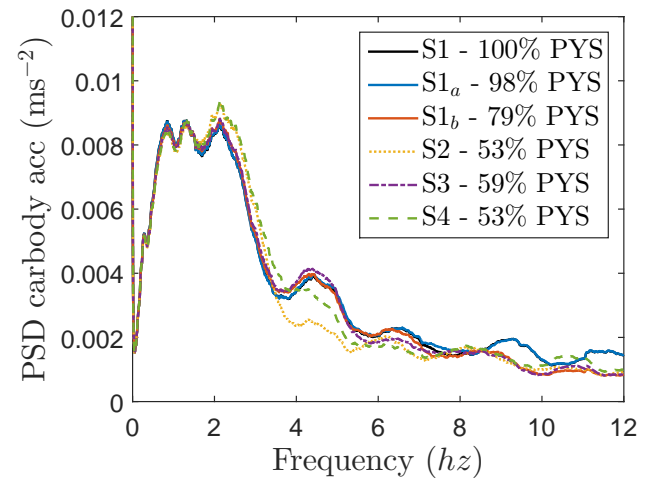

(a) Conicity 0.5.

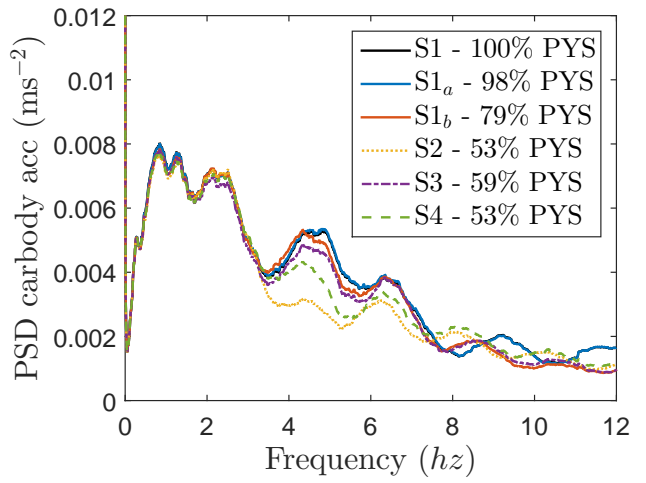

(b) Conicity 0.3 .

Figure 10. A PSD plot of Carbody acceleration for the cases with equivalent conicity 0.5 and 0.3 , at $33.5 \mathrm{~ms}^{-1}$.

\subsection{Reductions in Network Rail Variable Usage Charge (VUC)}

Reducing a vehicle's PYS improves curving performance, and therefore reduces rail surface damage (wear and rolling contact fatigue) during curving, due to lower values of $\mathrm{T}_{\gamma}$ (the frictional energy lost at the contact patch). The benefits can be assessed using the VUC. This is made up of charges arising from signals, tracks, other structures and surface damage, and is calculated using the Network Rail spreadsheet found in [1]. Figure 11 shows how the VUC (measured in pence/vehicle mile) changes when the inertance-integrated suspensions allow the PYS to be reduced. Note that only surface damage is affected by a reduced PYS. It can be seen that the S2 and S4 configurations with $53 \%$ PYS delivers a $26 \%$ reduction in VUC, whilst the $\mathrm{S}_{b}$ and $\mathrm{S} 3$ layouts, which respectively have a PYS of $59 \%$ and $79 \%$ give VUC reductions of $18 \%$ and $10 \%$. 


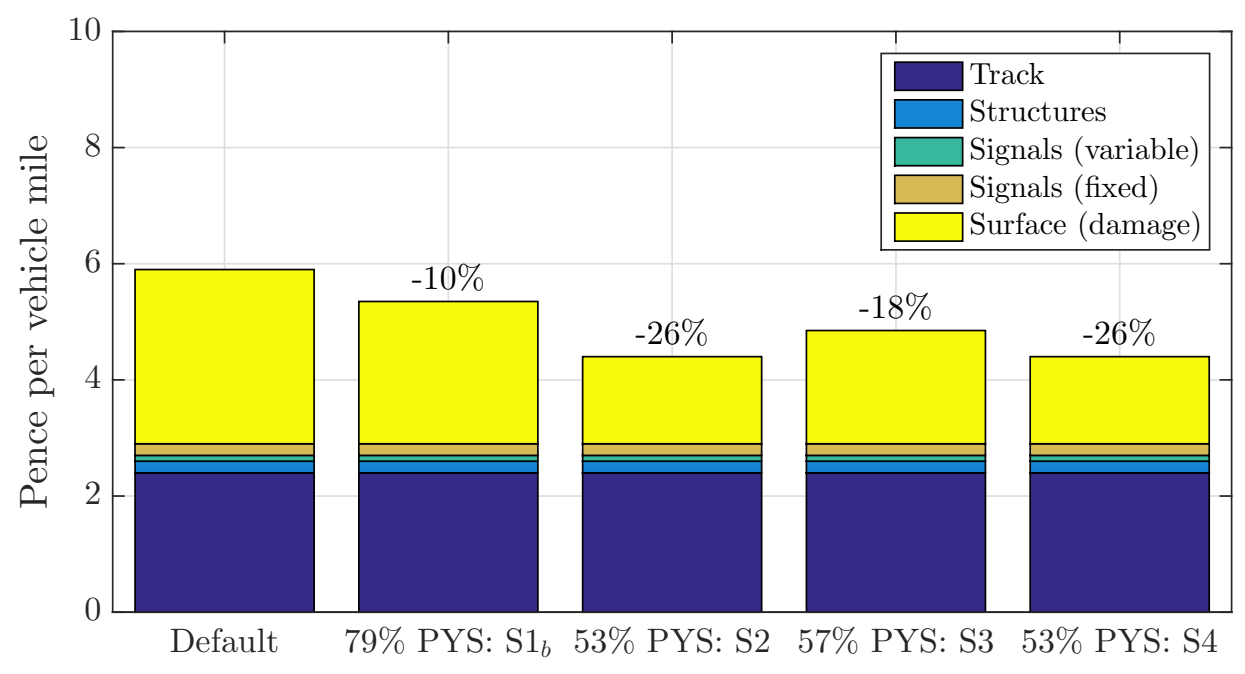

Figure 11. The effect that reducing the PYS has on the VUC.

\subsection{Additional Vehicle Dynamics Assessments Using Measured Contact Data}

This section considers the behaviour of vehicles with inertance-integrated suspensions in curved transitions and when subject to one-off peak lateral irregularities.

\subsubsection{Curve Transitions}

When a railway vehicle approaches a curve, the track is designed to transition from a straight line to a steady state curve. This can be achieved with a linear increase in the applied cant and rate of curvature (i.e. the inverse of curve radius). In the steadystate section of the curve, where the radius and cant do not change, the contact forces reduce with a reduced PYS (as implied in Section 4.2). In this section, the vehicle behaviour in curve transitions are considered to check whether the reduced PYS and optimised inerter-based suspensions will cause any unwanted behaviour. Simulations have been carried out for the vehicle approaching a $200 \mathrm{~m}$ radius curve, with a $100 \mathrm{~mm}$ applied cant running at at a speed of $18 \mathrm{~ms}^{-1}$ to give the maximum permitted cant deficiency of $150 \mathrm{~mm}$ [38]; a transition length of $40 \mathrm{~m}$ is used to give the worst-case cant gradient of 1:400 [38]. Vehicles with suspension layouts S2, S3, S4, as well as a default vehicle with PYS of $53 \%$ of the default value are compared. Here the default vehicle modified with a PYS of $53 \%$ is shown to allow us to see how the addition of optimised inerter-based lateral suspensions affects the overall dynamics. The vehicle is travelling through a right-hand curve, and a new P8 wheel [39] combined with a new CEN60E2 rail has been used in these simulations.

Figure 12 shows how the lateral contact forces for the right wheel on wheelset 1 and the left wheel on wheelset 2 (where the highest forces occur) on the front bogie vary during in a curve transition. Figures $12(\mathrm{a})$ and (c) show the whole of the initial transient period, whilst Figures 12(b) and (d) show the initial $2 \mathrm{~m}$ of this period. The forces for the $\mathrm{S}_{a}, \mathrm{~S} 2, \mathrm{~S} 3$ and $\mathrm{S} 4$ vehicles (with respective PYSs of 53\%, 59\%, 53\%, and $59 \%$ ) are largely similar for the majority of the $40 \mathrm{~m}$ duration, yet it can be seen from Figures 12(a) and (b) that the peak lateral forces for inertance-integrated layouts 


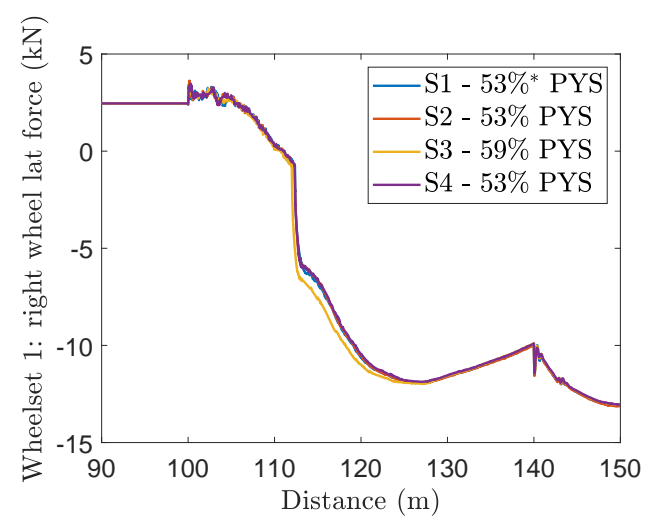

(a)

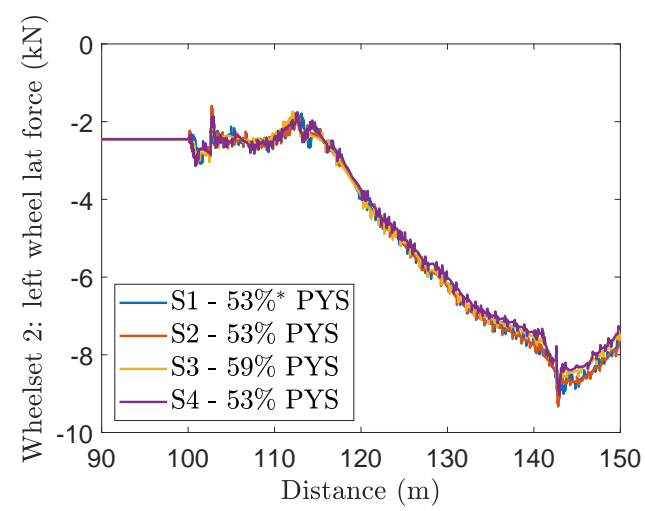

(c)

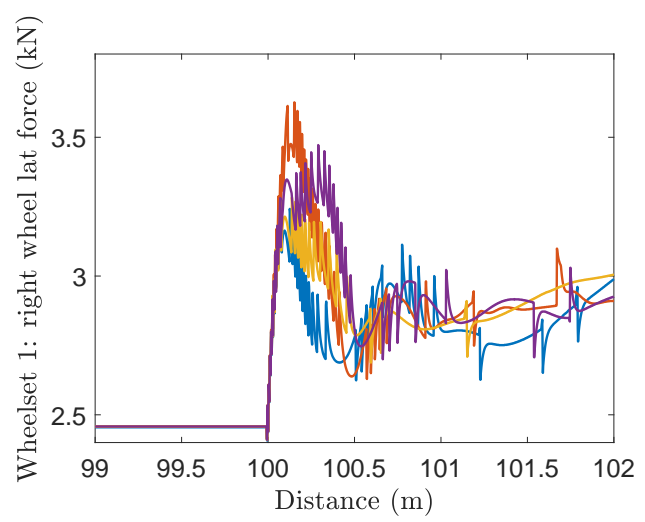

(b)

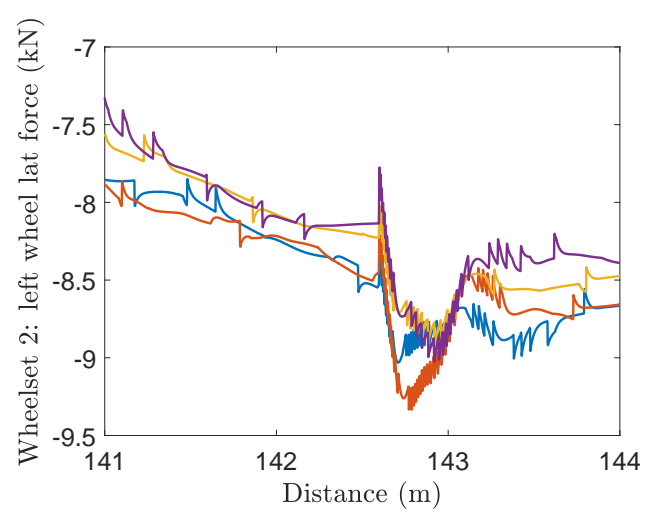

(d)

Figure 12. Lateral forces at the right (inner) wheel of wheelset 1 ((a) and (b)), and at the left (outer) wheel of wheelset 2 ((c) and (d)) in the initial section of the curve transition. (a) and (c) shows the full curve transition (from 100-140m), whilst (b) and (d) shows in more detail the initial lateral force variations at the start of the transition.

are slightly higher than for the default vehicle with $53 \%$ PYS, and the peaks are at a greater distance from the start of the transition. For the left wheel on the second wheelset, S2 gives the greatest peak lateral force whilst S3 and S4 display peak lateral forces similar in magnitude to the conventional vehicle with $53 \%$ PYS.

\subsubsection{One-Off Peak Lateral Irregularities}

To further investigate the lateral dynamic behaviour of the inertance-integrated suspensions, VAMPIRE ${ }^{\circledR}$ simulations have been carried out to replicate the lateral dynamic force calculation in the standard: GM/TT0088 Permissible Track Forces for Railway Vehicles [40]. GM/TT0088 states that the vehicle must not subject the track to lateral forces greater than:

$$
Y_{\max }=\frac{W}{3}+10,
$$

where $\mathrm{Y}$ is the lateral force transmitted per axle box, and $\mathrm{W}$ is the static axle-load. The BogiePassenger 39t 15yaw vehicle has a total vehicle mass of 29 tonnes; therefore an axle load of $96 \mathrm{kN}$, hence, using Equation 4 the maximum lateral force permissible per wheel is $42 \mathrm{kN}$. GM/TT0088 suggests that the lateral track force calculation must be 
performed on a vehicle travelling at its maximum speed, at maximum cant deficiency which then encounters a lateral kink with a gradient of 0.0039rad. The applied cant is $128 \mathrm{~mm}$, the curving radius is $600 \mathrm{~m}$, and the vehicle is travelling at $33.5 \mathrm{~ms}^{-1}$, giving a cant deficiency of $150 \mathrm{~mm}$. The kink has a total span of $6 \mathrm{~m}$, and consists of a lateral ramped track deflection of $11.7 \mathrm{~mm}$. For the simulations presented in this section, again, a new P8 wheel [39], combined with a new CEN60E2 rail has been used, and it should be noted that the kink occurs during the steady state section of the curve.

Figure 13 shows the sum of the lateral forces across the wheelset, $\Sigma Y$, when the vehicle passes through the kink. The outputs are filtered using a $2 \mathrm{~m}$ moving average, as GM/TT0088 states that only lateral forces that are sustained for distances of $2 \mathrm{~m}$ or more shall be taken into account in the analysis. It is shown that the inertanceintegrated suspension can increase the peak lateral forces, most notably when using the S4 layout, however, for every case it remains significantly lower than the GM/TT0088 limit of $42 \mathrm{kN}$.

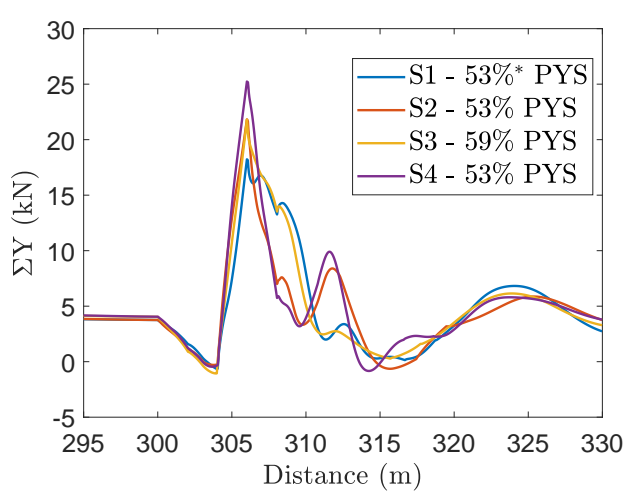

(a) Wheelset 1.

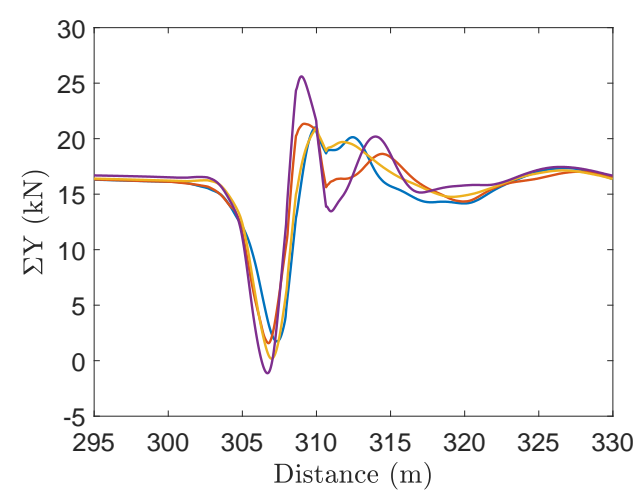

(b) Wheelset 2.

Figure 13. Total lateral wheelset force on wheelsets 1 and 2 , using a $2 \mathrm{~m}$ sliding window average, for the optimised inertance-integrated suspensions, and the default suspension layout but with $53 \%$ PYS.

\section{Conclusions}

This paper has investigated the potential for reducing PYS, without significantly compromising ride comfort, through the use of inerters in the primary suspension of a realistic four-axle railway vehicle model. The dynamics of a typical passenger vehicle are simulated in VAMPIRE ${ }^{\circledR}$ over a range of operational velocities and equivalent conicities, as these parameters significantly effect the vehicle dynamics. Using network-synthesis theory, a range of inertance-integrated layouts with pre-determined complexities were optimised and several beneficial configurations were identified. It has been shown that using optimised inertance-integrated primary suspensions enable the PYS to be reduced to $53 \%$ of its default value. A PYS reduction of this magnitude would allow the VUC to drop by $27 \%$ and hence provide significant financial benefit to the railway industry. It has been found that whilst the linear contact model (used in the optimisations) is very useful for increasing computational efficiency for the optimisation, it can over predict the lateral dynamic behaviour of railway vehicles, especially at higher equivalent conicities. Notwithstanding, when using linear contact modelling, for the case with the highest vehicle speed and wheel conicity, the RMS carbody acceleration was reduced by $18 \%$ comparing with the default value, and when 
nonlinear contact modelling checks were carried out, the largest reduction was $12 \%$. In addition, industrial measures such as curved transitions and one-off peak lateral irregularities have been assessed to demonstrate that the reduced PYS suspension meets the required performance. The design methodology developed in this study will be of great benefit for future studies concerning railway vehicle dynamics.

\section{Funding}

The authors would like to thank EPSRC (Grant Reference: EP/P013546/1) and the Rail Safety and Standards Board for funding this research.

\section{References}

[1] Network Rail, "Cp5 vuc calculator (current prices, february 2017)," tech. rep., Network Rail, 2017.

[2] M. Burstow, "VTAC calculator: Guidance note for determining $t_{\gamma}$ values," 2012. Available at https://cdn.networkrail.co.uk/wp-content/uploads/2016/12/VTAC-calculatorGuidance-note-for-determining-Tgamma-values.pdf.

[3] R. Goodall and T. X. Mei, "Mechatronic strategies for controlling railway wheelsets with independently rotating wheels," in 2001 IEEWASME International Conference on Advanced Intelligent Mechatronics Proceedings 6-12 July 2001 Como, Italy, pp. 225-230, 2001.

[4] T. X. Mei and R. M. Goodall, "Practical strategies for controlling railway wheelsets with independently rotating wheels," Journal of Dynamic Systems, Measurement, and Control, vol. 125, pp. 354-360, 203.

[5] T. X. Mei and R. M. Goodall, "Robust control for independently rotating wheelsets on a railway vehicle using practical sensors," IEEE Transactions on Control Systems Technology, vol. 9(4), pp. 599-607, 2001.

[6] M. Smith, "Synthesis of mechanical networks: The inerter," IEEE Transactions on Automatic Control, vol. 47(10), pp. 1648-1662, 2002.

[7] S. J. Swift, M. C. Smith, A. R. Glover, C. Papageorgiou, B. Gartner, and N. E. Houghton, "Design and modelling of a fluid inerter," International Journal of Control, vol. 86(11), pp. 2035-2051, 2013.

[8] R. Andrews, A. Duncan, T. Lewis, and E. Yang, "Design, manufacture and testing of fluid inerter devices," tech. rep., University of Bristol, 2015.

[9] X. Liu, J. Jiang, B. Titurus, A. Harrison, and D. McBryde, "Testing and modelling of the damping effects for fluid-based inerters," Procedia Engineering, vol. 199, pp. 435-440, 2017.

[10] M. Z. Q. Chen, C. Papageorgiou, F. Scheibe, F.-C. Wang, and M. C. Smith, "The missing mechanical circuit element," IEEE Circuits and Sytems Magazine, 2009.

[11] F.-C. Wang, M.-F. Hong, and Y. C. Lin, "Designing and testing a hydraulic inerter," IMECHE Mechanical Engineering Science, vol. 225, pp. 66-72, 2010.

[12] F. Scheibe and M. Smith, "Analytical solutions for optimal ride comfort and tyre grip for passive vehicle suspensions," Vehicle System Dynamics, vol. 47(10), pp. 1229-1252, 2009.

[13] S. Evangelou, D. J. N. Limebeer, R. S. Sharp, and M. C. Smith, "An h infinity loopshaping approach to steering control for high-performance motorcycles," Lecture Notes in Control and Information Sciences, vol. 329, pp. 257-275, 2006.

[14] J. Z. Jiang, M. Smith, and N. E. Houghton, "Experimental testing and modelling of a mechanical steering compensator," International Symposium on Communications, Control and Signal Processing, pp. 249-254, 2008.

[15] I. F. Lazar, S. A. Neild, and D. J. Wagg, "Using an inerter-based device for structural vi- 
bration suppression," Earthquake Engineering and Structural Dynamics, vol. 43, pp. 1129$1147,2014$.

[16] F.-C. Wang, C.-W. Chen, M.-K. Liao, and M.-F. Hong, "Performance analyses of building suspension control with inerters," 46th IEEE Conference on Decision and Control, 2007.

[17] S. Y. Zhang, J. Z. Jiang, and S. Neild, "Optimal configurations for a linear vibration suppression device in a multi-storey building," Structural Control and Health Monitoring, vol. 24, no. 3, pp. e1887-n/a, 2017. e1887 STC-16-0018.R2.

[18] Y. Li, C. Howcroft, S. Neild, and J. Jiang, "Using continuation analysis to identify shimmy-suppression devices for an aircraft main landing gear," Journal of Sound and Vibration, vol. 408, pp. 234-251, 112017.

[19] Y. Li, J. Jiang, and S. Neild, "Inerter-based configurations for main landing gear shimmy suppression," Journal of Aircraft, vol. 54, pp. 684-693, 32017.

[20] Y.-C. Chen, S.-Y. Wu, and F.-C. Wang, "Vibration control of a three-leg optical table by mechatronic inerter networks," SICE Annual Conference 2014, 2014.

[21] F.-C. Wang, M.-R. Hsieh, and H.-J. Chen, "Stability and performance analysis of a fulltrain system with inerters," Vehicle System Dynamics, vol. 50, no. 4, pp. 545-571, 2012.

[22] F.-C. Wang and M.-K. Liao, "The lateral stability of train suspension systems employing inerters," Vehicle System Dynamics, vol. 48, no. 5, pp. 619-643, 2010.

[23] J. Z. Jiang, A. Z. Matamoros-Sanchez, R. M. Goodall, and M. C. Smith, "Passive suspensions incorporating inerters for railway vehicles," Vehicle System Dynamics: International Journal of Vehicle Mechanics and Mobility, vol. 50:sup1), pp. 263-276, 2012.

[24] A. Z. Matamoros-Sanchez and R. M. Goodaoll, "Applications of the inerter in railway vehicle suspension," in 2014 UKACC International Conference on Control (CONTROL), pp. 555-560, July 2014.

[25] A. Z. Matamoros-Sanchez and R. M. Goodall, "Novel mechatronic solutions incorporating inerters for railway vehicle vertical secondary suspensions," Vehicle System Dynamics, vol. 53, no. 2, pp. 113-136, 2015.

[26] J. Jiang, T. Mei, and M. Smith, "Curving performance for railway vehicles with advanced passive suspensions," in 23rd International Symposium on Dynamics of Vehicle on Road and Tracks, IAVSD, 2013.

[27] J. Z. Jiang, A. Z. Matamoros-Sanchez, A. Zolotas, R. M. Goodall, and M. C. Smith, "Passive suspensions for ride quality improvement of two-axle railway vehicles," IMECHE: Journal of Rail and Rapid Transit, vol. 229(3), pp. 315-329, 2015.

[28] T. D. Lewis, J. Z. Jiang, S. A. Neild, C. Gong, and S. D. Iwnicki, "Using an inerter-based suspension to improve both passenger comfort and track wear in railway vehicles," Vehicle System Dynamics, vol. 0, no. 0, pp. 1-22, 2019.

[29] J. Evans, "Application of the hall hydraulic radial arm bush to a $200 \mathrm{~km} / \mathrm{h}$ inter-city coach," in International Symposium on Dynamics of Vehicle on Road and Tracks, IAVSD, 2011.

[30] Y. Zhao, G. Tucker, R. Goodall, S. Iwnicki, J. Jiang, and M. Smith, "Developing an inerter model using multibody dynamics software," in 25th International Symposium on Dynamics of Vehicle on Road and Tracks, IAVSD, 2017.

[31] RSSB Research Programme, "Vtism stage 2 summary report," tech. rep., RSSB, 2010.

[32] W. Klingel, "Uber den lauf der eisenbahnwagen auf gerader bahn," Organ fur die Fortschritte des Eisenbahnwesens in technischer Beziehung, vol. 20, pp. 113-123, 1883.

[33] British Standard, BS EN 15302:2008+A1:2010, Railway applications. Method for determining the equivalent conicity. 2008.

[34] S. Y. Zhang, J. Z. Jiang, and S. A. Neild, "The structure-immittance approach for passive vibration control," Procedia Engineering, vol. 199, pp. 1834 - 1839, 2017. X International Conference on Structural Dynamics, EURODYN 2017.

[35] X. Liu, J. Z. Jiang, B. Titurus, and H. J Andrew, "Model identification methodology for fluid-based inerters," Mechanical Systems and Signal Processing, vol. 106, 012018.

[36] S. J. Swift, M. C. Smith, A. R. Glover, C. Papageorgiou, B. Gartner, and N. E. Houghton, "Design and modelling of a fluid inerter," International Journal of Control, vol. 86, no. 11, 
pp. 2035-2051, 2013.

[37] Research and Development Programme RSSB, "Controlling rail vertical contact stresses," tech. rep., RSSB, 2011.

[38] Railway Group Standard, "Track system requirements: Gc/rt5021," 2011.

[39] British Railways Board, "Railway wheelsets: Gmrt2466," 2017.

[40] British Railways Board, "Permissible track forces for railway vehicles: Gmtt0088," 1993. 